\title{
CHARACTERISTICS STUDY ON SUB GRADE SOIL BLENDED WITH GROUND GRANULATED BLAST FURNACE SLAG
}

\author{
A. Manimaran, Seenu Santhosh and P.T.Ravichandran* \\ Department of Civil Engineering, Faculty of Engineering and Technology, SRM Institute of \\ Science and Technology, Kattankulathur-603203, Tamil Nadu, India \\ *E-mail: ptrsrm@gmail.com
}

\begin{abstract}
Construction field is booming with high standard innovative technologies. Unfortunately, a massive percentage of a downgrade is noticed afresh, due to the instability of soil. More concern is given by geotechnical engineer on expansive soils, as it causes significant hazards to foundations due to the volume change nature of the soil. To ensure adequate sub grade stability, soil stabilization is one of the proactive methods to rectify the instability problems and in the account of this, to advocate sustainability, admixtures of more rewarding and less impactful to nature is advisory. Thus in support of this, a thorough experimental study was executed in this work to figure out the potential industrial waste Ground Granulated Blast furnace Slag (GGBS) as a stabilizing agent. In order to assess the sub grade strength attainment rate, California Bearing Ratio (CBR) test was conducted on soil treated with GGBS $(2.5 \%, 5 \%, 7.5 \%$, and $10 \%$ ) at different curing periods of 3, 7, and 14 days. Free Swell Test was conducted to elucidate the difference in swelling behavior of treated soil with admixtures. The test results showed the uptrend in CBR value as well as a decrement in swell percentage to a higher extent with prolonged curing and various dosages of admixture content thus gave a stamp of approval to the stabilization mechanism involving pozzolanic reactions. Thus this paper highlights the optimized exploitation of bounded resources by restraining the irrelevant propagation of waste.
\end{abstract}

Keywords: CBR value, GGBS, Free Swell Test.

(C) RASĀYAN. All rights reserved

\section{INTRODUCTION}

A well-known fact which can be further brought in to spotlight is expansive soil. The ingress of water in expansive soil cause the upheavals, thus can be marked as the worst enemy of pavement constructions. In order to resolve this trouble at global level innovative ideas came into existence. In the present scenario, soil stabilization technique has been considered as one of the suitable methods of treating expansive soil. ${ }^{1}$ Many techniques are being practiced which was successfully reported by many researchers using various admixtures. The compounded use of many industrial wastes like cement kiln dust, fly ash, phosphogypsum etc. have shown a high rate of attainment of strength. ${ }^{2}$ The financial up growth in developing countries made industrialization at the top, thus the cost of materials increased. As an alternative solution, for bulk works, other forms of industrial waste are preferred than lime, cement and industrial waste ${ }^{3-6}$. It is also ratified that the presence of sulfate in lime, causes the formation of ettringite and thaumasite, which in turn induces high swelling in soil. ${ }^{7}$

Industrial waste materials like GGBS, phospho gypsum, copper slag etc. ${ }^{8}$ are the by-products from industries utilized by the various researchers had done studies to stabilize the soil showing the results showed an uptrend in strength and decrement in swelling behavior of expansive soil. Taking into consideration all these facts, this study is mainly focussing on promoting sustainable development with the compounded usage of admixture GGBS in the stabilization process.

\section{EXPERIMENTAL}

Materials and Methods

For the present study soil sample, labeled as S1, was dug out from Madhuvancherry, Villupuram district from deeper depth by disturbed sampling method. It was then dried in open area and ground. A set of allencompassing laboratory test was performed to elucidate the geotechnical properties of the soil sample. All 
the results were thoroughly inferred in accordance with Indian Standard. ${ }^{9}$. The soil sample S1 was found to have $240 \%$ swelling and it falls into inorganic clay having high compressible $(\mathrm{CH})$ nature. ${ }^{10,11}$ The specific gravity of the soil was found to be $2.66 .^{12}$ From the compaction test results, Maximum Dry Density and Optimum Moisture Content were obtained as $1.61 \mathrm{~g} / \mathrm{cc}$ and $21 \%{ }^{13}$ and it was used in achieving the UCC Value of the virgin soil as $142 \mathrm{kPa} .{ }^{14}$

In favor of management of solid waste, in this work, an effort was made to check the relevance of Ground Granulated Blast furnace Slag (GGBS) in the stabilization process. The slag obtained as the by-product during production of iron manufacturing, at an operating temperature of $1500^{\circ} \mathrm{C}$, in a molten state was tapped off from the surface was cooled and ground to obtain GGBS.

\section{Effectualness of GGBS on California Bearing Ratio}

\section{RESULTS AND DISCUSSION}

The stability of subgrade can be finalized once the CBR test results give green signal, as CBR value is one of the inevitable parameters in deciding the pavement thickness. For the proposed work, samples were prepared and tested with and without treating with admixture GGBS. The treated samples were simultaneously kept for curing of 3, 7 and 14 days by covering with wet gunny bags and maintained at room temperature. The samples were tested, according to IS code specifications, after soaking for 96 hours. The load-penetration graph was plotted and is given in Fig.-1. It can be seen that when $2.5 \%$ and $5 \%$ of GGBS was added there is no much variation in CBR value, but once the GGBS content increased to optimum of $10 \%$ with curing of 7 days there is a tremendous rise in CBR value indicating the high pozzolanic reaction with respect to time. The sharp rising zone curve indicates the potential of GGBS in initiating proactive energy leading to hardening of clay. A maximum of CBR value of 25 is observed at optimum percentage indicating the escalation nature of strength from CBR value of 3.6 of virgin soil to 25 with the addition of admixture GGBS.

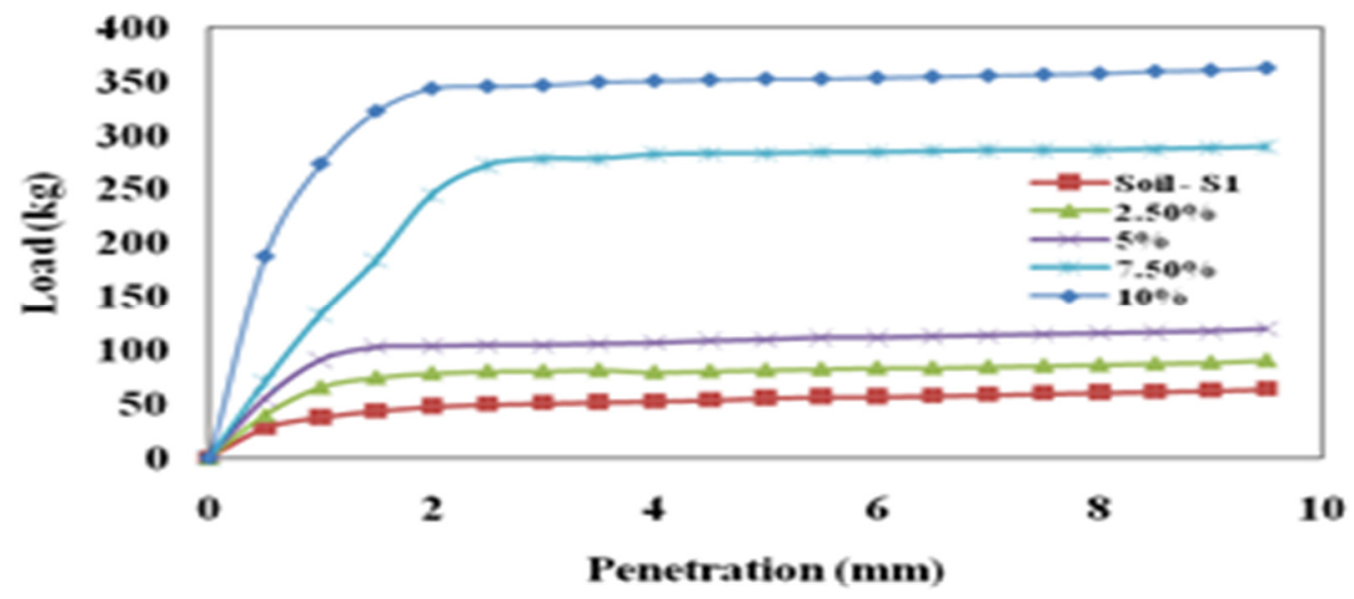

Fig.-1: Load - Penetration curve for soil sample (S1) treated with GGBS of varying dosages at 7-day curing

In addition to load-penetration plot the uptrend in strength was studied by introducing Admixture Influence Factor (AIF), which shows the approximate rise in sub grade strength with various dosages of admixture content, whose relationship is mentioned as a below:

$$
\text { Admixture Influence Factor(AIF) }=\frac{\text { CBR Value of Untreated soil }}{\text { CBR Value of Treated Soil }} \times 100
$$

The percentage increase in AIF is graphically represented in Fig.-2. It can be observed that at lower percentages of GGBS content the increasing trend of CBR value was not much effective. For the 7 and 14 days curing the percentage, increment can be highly pronounced as it goes up to $842 \%$ with respect to a 
RASĀYAN $J$. Chem.

Vol. 11 | No. 1 | 401 - 404 | January - March | 2018

higher dosage of $10 \%$ GGBS . At this moment it can be justified that the high availability of calcium content, as well as the high activation energy of admixture GGBS, lead to the commencement of pozzolanic reactions. The overall percentage rise is tabulated below representing the AIF \% in Table- 1 .

\section{Swell Characteristics}

Free Swell Index is the increment in volume of the soil, without any external restraints, when flooded in water. The Swell Index or Free Swell test procedure is used to determine the general swelling characteristics of soils. The swell test was conducted using pulverized soil sample which was taken from treated specimen after conducting the test. The swell samples were kept undisturbed for 24 hours. The swell characteristics of soil sample S1 were found out for both treated and untreated samples according to the standard IS:2720.
15

Table-1: AIF (\%) of Soil Treated with GGBS

\begin{tabular}{c|c|c|c|c|c}
\hline \multirow{2}{*}{ Soil Sample } & Curing Days & \multicolumn{4}{|c}{ Admixture Influence Factor, $\%$} \\
\hline \multirow{3}{*}{ S1 } & & \multicolumn{4}{|c}{$G G B(\%)$} \\
\cline { 2 - 5 } & & $2.5 \%$ & $5 \%$ & $7.5 \%$ & $10 \%$ \\
\cline { 2 - 6 } & 3 & 47 & 53 & 92 & 111 \\
\cline { 2 - 6 } & 7 & 64 & 111 & 386 & 597 \\
\cline { 2 - 6 } & 14 & 77 & 469 & 670 & 842 \\
\hline
\end{tabular}

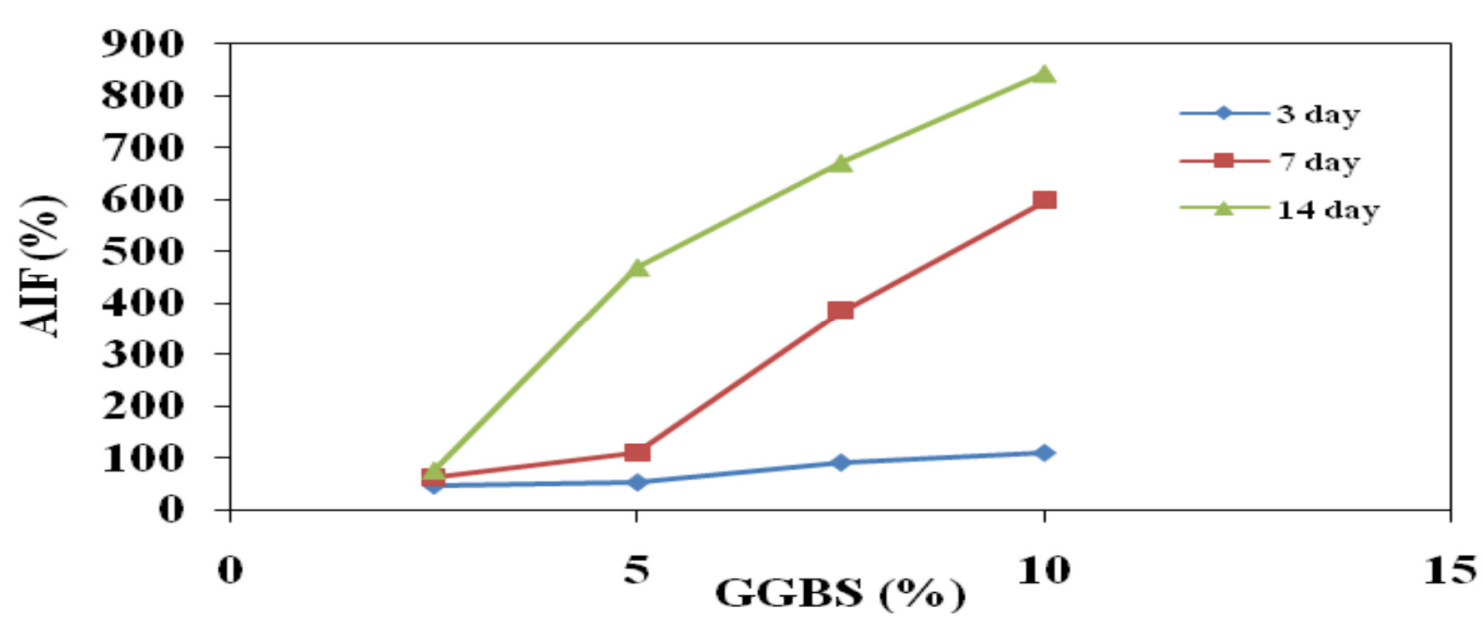

Fig.-2: Depiction of Admixture Influence Factor (\%) for S1 treated with GGBS of varying dosages at various curing periods

Table-2: Swell Characteristics of Soil Treated with GGBS

\begin{tabular}{l|c|c|c|c|c|c}
\hline Soil Sample & Curing Days & \multicolumn{5}{|c}{ Free Swell Index (\%) } \\
\hline \multirow{3}{*}{ S1 } & & \multicolumn{5}{|c}{ GGBS (\%) } \\
\cline { 2 - 7 } & & $0 \%$ & $2.5 \%$ & $5 \%$ & $7.5 \%$ & $10 \%$ \\
\cline { 2 - 7 } & 0 & 240 & & & & \\
\cline { 2 - 5 } & 3 & & 220 & 180 & 130 & 110 \\
\cline { 2 - 6 } & 7 & & 200 & 160 & 120 & 90 \\
\cline { 2 - 5 } & 14 & & 160 & 130 & 110 & 70 \\
\hline
\end{tabular}

From the Table-2, it was observed that the free swell of virgin soil decreased from $240 \%$ to $70 \%$, when the GGBS content was increased to $7.5 \%$ at a curing period of 7 days. Water content variation may cause shrinking and heaving of soil, and when it persists the surface of ground cracks and pulls away. Thus a decreasing trend of the free swell was observed with the addition of admixture GGBS. The formation of cementitious compounds may have made the soil particles to arrange into a coarse flocculated structure, 


\section{RASĀYAN J. Chem.}

Vol. 11 | No. 1 | 401 - 404 | January - March | 2018

which ultimately resulted in a reduction of a swell percent. The high shrink-swell capacity of soil got reduced and thus it can be predicted that the ability to drastically change volume was highly diminished with the addition of GGBS.

\section{CONCLUSION}

The elevation in engineering properties of the soil was obtained when treated with GGBS. The following conclusions were drawn from this study:-

- The clayey soil blended with admixture GGBS enhanced the subgrade stability by giving the maximum CBR value of 25 with varied dosages of GGBS and various curing periods.

- The influence of admixture was analyzed with the introduction of AIF which shows the percentage rise in CBR value is about $842 \%$ respectively.

- It can be predicted that, compared to cement, lime, Fly Ash etc. dramatically higher strength attainment is observed in GGBS due to the formation of cementitious products.

- The swelling percent decreased with an upsurge in the binder content, GGBS and with curing period temperature.

- Thus based on the above-mentioned results, it can be concluded that, the remarkable influence of GGBS in clayey soil, thus made the weaker soil suitable for pavement construction with high bearing capability.

\section{REFERENCES}

1. Gyanen. Takhelmayum, Savitha.A.L, Krishna Gudi, International Journal of Engineering Science and Innovative Technology, 477, 481(2013).

2. Divya Krishnan K, Ravichandran P.T, Janani V, Annadurai R, Manisha Gunturi. Indian Concrete Journal,81,86(2015).

3. Manjunath K R , Rohith L, International Research Journal of Engineering and Technology,155, 159 (2015).

4. Ece Celik, Zalihe Nalbantoglu, Engineering Geology, 20, 25 (2013).

5. G. Rajasekaran, Ocean Engineering,1133, 1159 (2015).

6. L.Krishnaraj, R.Suba Lakshmi and P.T.Ravichandran, Rasayan Journal of Chemistry, Vol.10(2), 592,599(2017).

7. Gupta, S, and Seehra, S. S., Highways Research Board, Bulletin, No. 38.,81, 97(1989).

8. Divya Krishnan K, P.T. Ravichandran and V. K. Gandhimathi, Rasayan Journal of Chemistry,10(2), 600, 605(2017).

9. IS: 1498-1970, Classification and identification of soils for general engineering purposes, Bureau of Indian Standards, New Delhi.

10. IS: 2720 (Part I), Methods of Test for Soil - Preparation of dry soil sample for various tests, Bureau of Indian Standards, New Delhi, (1983).

11. IS: 2720 (Part V), Methods of Tests for Soil: Determination of liquid limit and plastic limit, Bureau of Indian Standards, New Delhi, (1985).

12. IS: 2720 (Part III), Methods of Tests for Soil - Determination of specific gravity, Bureau of Indian Standards, New Delhi, (1987).

13. IS: 2720 (Part VII), Methods of Tests for Soil - Determination of water content-dry density relation using light compaction, Bureau of Indian Standards, New Delhi, (1987).

14. IS: 2720 (Part X), Methods of tests for Soil: Determination of unconfined compressive strength, Bureau of Indian Standards, New Delhi, (1973).

15. IS: 2720 (Part XL), Methods of Tests for Soil - Determination of free swell index of soil, Bureau of Indian Standards, New Delhi, (2002).

[RJC-2044/2017] 